\title{
Allogeneic stem cell transplantation in poor prognosis peripheral T-cell lymphoma: the impact of different donor type on outcome
}

\author{
Luca Castagna $\mathbb{1}^{1}$ - Thomas Pagliardini ${ }^{2}$ - Stefania Bramanti ${ }^{1} \cdot$ Jean Marc Schiano de Colella $\mathbb{C}^{2}$. \\ Catalina Montes de Oca ${ }^{2} \cdot$ Reda Bouabdallah ${ }^{2} \cdot$ Jacopo Mariotti $^{1} \cdot$ Sabine Fürst ${ }^{2} \cdot$ Angela Granata $^{2}$. \\ Chiara De Philippis ${ }^{1} \cdot$ Samia Harbi ${ }^{2} \cdot$ Barbara Sarina $^{1} \cdot$ Faezeh Legrand $^{2} \cdot$ Valerio Maisano $^{2} \cdot$ Pierre Jean Weiller $^{2}$. \\ Christian Chabannon $\mathbb{1}^{3} \cdot$ Carmelo Carlo-Stella ${ }^{1,4} \cdot$ Armando Santoro ${ }^{1,4} \cdot$ Didier Blaise $\mathbb{E}^{2} \cdot$ Raynier Devillier $\mathbb{E}^{2}$
}

Received: 15 June 2020 / Revised: 8 September 2020 / Accepted: 2 November 2020 / Published online: 15 November 2020

(c) The Author(s), under exclusive licence to Springer Nature Limited 2020

\begin{abstract}
We report the outcome of 68 patients with advanced peripheral T-cell lymphoma receiving transplantation from haploidentical or from conventional donors. The 4-year OS, PFS, 2-year cumulative incidence of relapse and 2-year GRFS was $75 \%, 70 \%, 21 \%$, and $51 \%$, respectively. Survival was not affected by donor type. The 2-year NRM was 9\%, lower after related or haploidentical donor $(21 \%$ vs $0 \%$ vs $7 \% ; p=0.06)$. Grade $2-4$ aGVHD cumulative incidence was significantly different after transplantation from haploidentical vs matched sibling vs unrelated donor, and (24\% vs $35 \%$ vs $58 \%, p=$ 0.024). The familial donor cohort was compared to the unrelated cohort. Familial donor induced less grade $2-4$ aGVHD, with a trend to less grade 3-4 aGVHD or moderate-severe cGVHD. The OS and PFS were not different, while the relapse risk and NRM were reduced. Allo-SCT is highly effective in T-cell lymphoma, with low NRM and low relapse rate. The incidence of aGVHD was lower after haploidentical transplantation. Related donor may challenge unrelated transplant reducing the risk of relapse and NRM.
\end{abstract}

\section{Background}

Peripheral T-cell non-Hodgkin lymphomas (PTCL) account for $\sim 10 \%$ of aggressive non-Hodgkin lymphoma cases [1]. The prognosis of PTCL is unfavorable, with the remarkable exception of ALK-positive cases. Currently, 5-year disease-

Supplementary information The online version of this article (https:// doi.org/10.1038/s41409-020-01133-5) contains supplementary material, which is available to authorized users.

$\triangle$ Luca Castagna

luca.castagna@humanitas.it

1 Humanitas Clinical and Research Center, IRCCS, via Manzoni 56, 20089 Rozzano, Milan, Italy

2 Haematology Department, Institut Paoli-Calmettes, Aix-Marseille Université, Marseille, France

3 Centre for Clinical Investigation in Biotherapy, Institut PaoliCalmettes, Aix-Marseille University, INSERM CBT 1409, Marseille, France

4 Department of Biomedical Sciences, Humanitas University, Via Rita Levi Montalcini 4, 20090 Pieve Emanuele, Milan, Italy free survival for PTCL after conventional first-line chemotherapy is $\sim 30 \%$ [2]. Although no prospective randomized trial was performed, prospective studies suggest, when feasible, that the use of high-dose chemotherapy (HDC) with autologous stem cell transplantation as consolidation therapy in first-line therapy can improve the survival rate to $50-60 \%[3,4]$.

In patients with relapse or refractory $(\mathrm{R} / \mathrm{R}) \mathrm{PTCL}$, the outcome is dismal (median overall survival (OS), 5 months) regardless of the selected salvage regimen, as reported by the MD Anderson [5, 6] and the Swedish Lymphoma Registry (median OS, 6 months) [7]. OS has not been influenced by recently introduced drugs, such as BV, romidepsine, belinostat, and palatrexate [8].

In the setting of R/R PTCL, allogeneic stem cell transplantation (allo-SCT) remains the only treatment that can significantly lead to long term DFS, as reported in several retrospective analyses [9-12]. Recently, Loirat et al. reported the results from an intent-to-treat analysis of upfront allo-SCT for PTCL showing promising outcome (5year OS 72\%) when allo-SCT was actually performed [13].

The development of T-cell replete allo-SCT from haploidentical donors (haplo-SCT) using post-transplantation 
cyclophosphamide (PT-Cy) as part of GVHD prophylaxis has allowed a wide extension of transplantation possibilities to treat hematological malignancies. In Europe and the USA, this platform [14] is the most popular, leading to low incidences of GVHD and NRM. In the specific context of lymphoma patients (HL and NHL), several papers [15-24] reported promising outcome after PT-Cy Haplo-SCT, confirming that this procedure is a valuable alternative to matched sibling (MSD) or unrelated (URD) donor alloSCT. However, few patients in these cohorts were affected by PTCL.

Here, we analyzed the outcome of Haplo-SCT in patients affected by R/R PTCL and we compared them with those obtained in patients receiving allo-SCT from a MSD or URD during the same period of time.

\section{Patients and methods}

We identified 68 patients with PTCL between 2010 and 2019. All histological diagnoses of PTCL subtypes according to the World Health Organization criteria are represented. The retrospective collection and analysis of patient data from internal transplantation database were approved by the ethical committee of the institutional review board (NHLT-Haplo-IPC 2020-033). All patients signed informed consent.

Patients were candidates for allo-SCT when they met the following criteria: relapse after HDC; relapse or refractory after conventional chemotherapies; lack of mobilization of autologous stem cells in first-line remission; high risk of relapse based on clinical characteristics. In the absence of a MSD or URD, patients were candidates for transplantation from a haploidentical donor (HAPLOD). General eligibility criteria to proceed to allo-SCT were absence of uncontrolled infections, low Karnofsky performance status $(<60 \%)$, absence of severe organ dysfunction, including a left ventricular ejection fraction $<40 \%$, diffusion lung capacity for carbon monoxide or Forced expiratory volume $<50 \%$, or creatinine clearance $<50 \mathrm{~mL} / \mathrm{min}$. The hematopoietic stem cell comorbidity index (HCT-CI) was calculated for each patient [25].

Conditioning regimen for haplo-SCT were either nonmyeloablative (NMAC) —associating fludarabine $30 \mathrm{mg} / \mathrm{m}^{2}$ from day -6 to day -2 , cyclophosphamide (Cy) $14.5 \mathrm{mg} / \mathrm{kg}$ on days -5 and -6 ) and 2 Gy total body irradiation on day -1 - or reduced intensity (RIC) consisting of thiotepa $5 \mathrm{mg} /$ $\mathrm{kg}$ on day- 6 , fludarabine $30 \mathrm{mg} / \mathrm{m}^{2}$ from day- 5 to day- 2 , and iv eusulfan $3.2 \mathrm{mg} / \mathrm{kg}$ on day-4 and day-3) regimens. GVHD prophylaxis was based on PT-Cy $50 \mathrm{mg} / \mathrm{kg}$ on day +3 and day +4 , tacrolimus or cyclosporine A (CsA) and mycophenolate mofetil from day +5 , as previously described.
For allo-SCT from MSD and URD, two RIC regimens were used: fludarabine $30 \mathrm{mg} / \mathrm{m}^{2}$ (day -6 to day -2 ), iv busulfan $3.2 \mathrm{mg} / \mathrm{kg}$ (day -5 to day -4 ) and ATG $2.5 \mathrm{mg} / \mathrm{kg}$ (day - 1). thiotepa $6 \mathrm{mg} / \mathrm{kg} \times 2$, Cy $30 \mathrm{mg} / \mathrm{kg}$ (day -4 to day +3 ), fludarabine $30 \mathrm{mg} / \mathrm{m}^{2}$ (day -4 to day -3 ), and ATG $(2.5 \mathrm{mg} / \mathrm{kg} / \mathrm{day}$ on day -3 and -2$)$. Post-transplant GVHD prophylaxis consisted of CsA from $\mathrm{d}-1$. Four patients receiving MSD did not receive ATG. Four patients received NMAC because of high HCT-CI and/or relapse after high-dose chemotherapy.

Acute GVHD was graded according to the Keystone criteria [26], and chronic GVHD was graded following NIH criteria [27].

\section{Engraftment}

Neutrophil recovery was defined as an absolute neutrophil count (ANC) $>0.5 \times 10^{9} / \mathrm{L}$ for three consecutive days without growth factor support. Platelet recovery was defined as a platelet count of $20 \times 10^{9} / \mathrm{L}$, without transfusions in the previous 7 days.

\section{Statistical considerations}

Outcomes were calculated from the date of allo-SCT. The Kaplan-Meier method was used for OS and progession free survival (PFS) analyses and univariate comparisons were made using log-rank test. PFS is defined as the time from starting allo-SCT to the first documented disease recurrence by radiological assessment or death due to any cause whichever occurs first. OS is defined as the time from starting the date of allo-SCT to death due to any cause. Patients were censored at last contact in absence of relevant events. We calculated GVHD and relapse free survival (GRFS) using a composite end point considering relapse, death, grade 3-4 acute GVHD, and moderate to severe chronic GVHD as relevant events. The cumulative incidences of GVHD, NRM and disease progression (or relapse) were computed using the Prentice method taking into account the presence of competing risk (death from any cause for GVHD while NRM and relapse were considered as mutually competing events). Univariate comparisons were performed using Grey test. Cox regression was performed to adjust the impact of donor type on outcome by including age (continuous variable) and disease status at the time of allo-SCT (CR vs. PR or less) in the model. In complement of per donor-group analysis, using a practical approach, we performed a second analysis of these data comparing familial $(\mathrm{MSD}$ and haploidentical donor $=\mathrm{RD}$ ) and URD.

All statistical analyses were performed using R-project software (https://www.r-project.org/). 
Table 1 Patient characteristics.

\begin{tabular}{|c|c|c|c|c|}
\hline & All $N=68$ & HAPLOD $N=29$ & $\operatorname{MSD} N=20$ & URD $N=19$ \\
\hline Median age & $56(20-70)$ & $59(25-68)$ & $51(28-68)$ & $51(21-70)$ \\
\hline \multicolumn{5}{|l|}{ Histological subtypes } \\
\hline T NOS & $25(37 \%)$ & $14(48 \%)$ & $8(40 \%)$ & $3(16 \%)$ \\
\hline AITL & $18(26 \%)$ & $5(17 \%)$ & $5(25 \%)$ & $8(42 \%)$ \\
\hline ALCL ALK- & $4(6 \%)$ & $2(7 \%)$ & l & $2(11 \%)$ \\
\hline ALCL ALK + & $8(12 \%)$ & $3(10 \%)$ & $2(10 \%)$ & $3(16 \%)$ \\
\hline ALCL ALK unknown & $1(1 \%)$ & I & I & $1(5 \%)$ \\
\hline $\mathrm{SS} / \mathrm{MF}$ & $5(7 \%)$ & $1(3 \%)$ & $3(15 \%)$ & $1(5 \%)$ \\
\hline T gamma-delta & $3(4 \%)$ & $2(7 \%)$ & l & $1(5 \%)$ \\
\hline NK nasal type & $2(3 \%)$ & $1(3 \%)$ & $1(5 \%)$ & l \\
\hline Others & $2(3 \%)$ & $1(3 \%)$ & $1(5 \%)$ & l \\
\hline Median lines CT & $3(1-7)$ & $3(1-5)$ & $2.5(1-7)$ & $3(1-5)$ \\
\hline Previous AUTO & $19(28 \%)$ & $8(26 \%)$ & $6(30 \%)$ & $5(26 \%)$ \\
\hline Previous ALLO & 1 & 1 & l & l \\
\hline Tandem auto-allo & 3 & 1 & 1 & 1 \\
\hline \multicolumn{5}{|l|}{ Disease status at ALLO } \\
\hline $\mathrm{CR}$ & $50(74 \%)$ & $19(66 \%)$ & $16(80 \%)$ & $15(79 \%)$ \\
\hline PR & $14(21 \%)$ & $8(28 \%)$ & $2(10 \%)$ & $4(21 \%)$ \\
\hline $\mathrm{SD} / \mathrm{PD}$ & $4(5 \%)$ & $2(7 \%)$ & $2(10 \%)$ & / \\
\hline \multicolumn{5}{|l|}{ HCT-CI } \\
\hline$\geq 3$ & $38(56 \%)$ & $17(59 \%)$ & $10(50 \%)$ & $11(58 \%)$ \\
\hline \multicolumn{5}{|l|}{ Donor type } \\
\hline HaploD & $29(43 \%)$ & 29 & 20 & 17 \\
\hline MSD & $20(29 \%)$ & & & 2 \\
\hline URD & $17(25 \%)$ & & & \\
\hline mURD & $2(3 \%)$ & & & \\
\hline \multicolumn{5}{|l|}{ Conditioning regimen } \\
\hline NMAC & $27(40 \%)$ & $25(86 \%)$ & $2(10 \%)$ & $2(11 \%)$ \\
\hline RIC & $41(60 \%)$ & $4(14 \%)$ & $18(90 \%)$ & $17(89 \%)$ \\
\hline \multicolumn{5}{|l|}{ Stem cell source } \\
\hline PBSC & $58(85 \%)$ & $21(72 \%)$ & $19(95 \%)$ & $18(95 \%)$ \\
\hline $\mathrm{BM}$ & $10(15 \%)$ & $8(28 \%)$ & $1(5 \%)$ & $1(5 \%)$ \\
\hline
\end{tabular}

NOS not otherwise specified, AITL angioimmunoblastic T cell lymphoma, ALCL anaplastic large cell lymphoma, $C R$ complete remission, $P R$ partial remission, $S D$ stable disease, $P D$ progressive disease, $H C T$ $C I$ hematopoietic cell transplantation-comorbidity index, HAPLOD haploidentical donor, MSD matched sibling donor, $U R D$ matched unrelated donor, $m U R D$ mis-matched unrelated donor, NMAC nonmyeloablative conditioning, $R I C$ reduced intensive conditioning, $P B S C$ peripheral blood stem cell, $B M$ bone marrow

\section{Results}

A total of 68 PTCL patients were included in this study. Patient characteristics are reported in Table 1. Twentynine patients received transplantation from HAPLOD (43\%), 20 (29\%) from MSD, and 19 from URD (28\%). At the time of allo-SCT, $50(74 \%)$ and $14(21 \%)$ patients were in complete (CR) and partial remission (PR), respectively. The median follow-up was 55 months (range 12-116).

\section{Engraftment and chimerism}

The median time to obtain unsupported ANC and platelet count was 18 days (range 8-57), and 15 days (range 8-257), respectively. Sixty-one patients $(90 \%)$ were evaluable for chimerism and 4 (7\%, 3 after allo-SCT from MDS and 1 after haplo-SCT) obtained mixed chimerism and 57 (93\%) full donor chimerism. Chimerism was not obtained in seven patients because of early death [4] and unavailability of results [3]. 

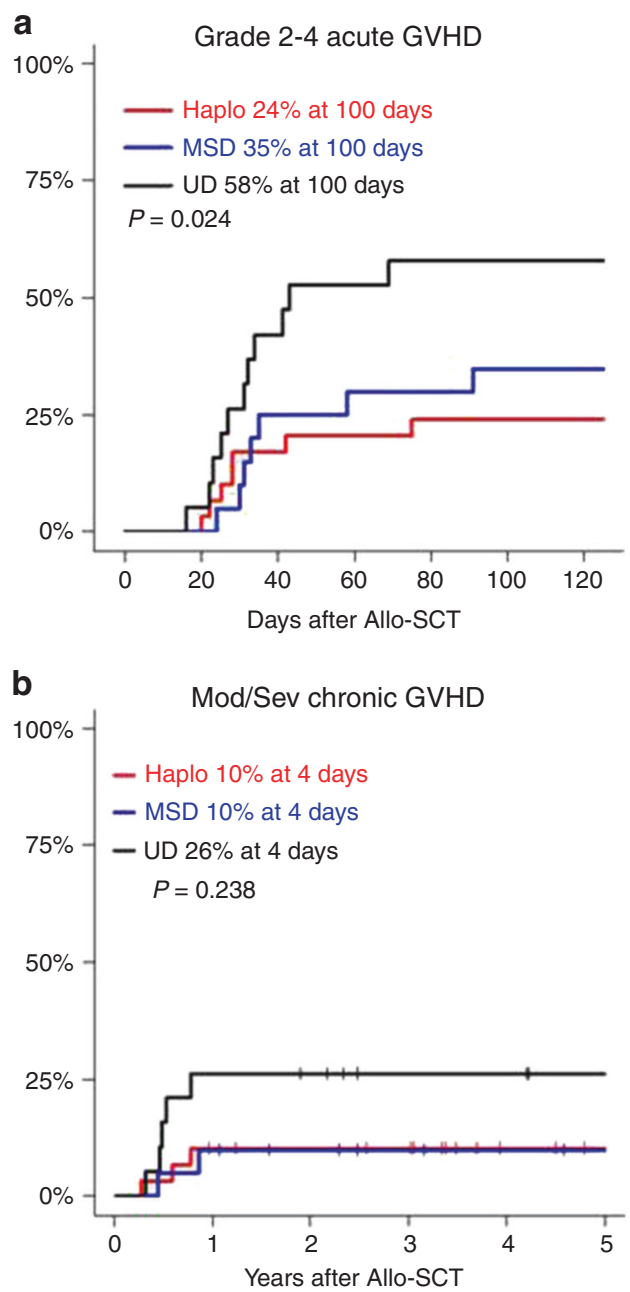

Fig. 1 Cumulative incidence of GVHD. a Grade 2-4 acute GVHD; b moderate/severe chronic GVHD.

\section{Acute and chronic GVHD}

For the whole population, the cumulative incidence of grade 2-4 and grade 3-4 aGVHD was 37\% (95CI: 27-50) and 10\% (95CI: 5-21), respectively. The 2-year cumulative incidence of moderate/severe cGVHD was $15 \%$ (95CI: $8-26)$. The cumulative incidence of grade $2-4$ aGVHD was significantly lower after haplo-SCT compared to MSD and URD allo-SCT (Haplo 24\% vs MSD 35\% vs URD 58\%, $p=0.024$, Fig. 1A). Although not significant, we observed a lower incidence of grade 3-4 aGVHD in the HAPLOD group (3\%), while corresponding value for MSD and URD groups were $15 \%$ and $16 \%$, respectively (global $p=0.17$ ) (Table 2). The cumulative incidence of moderate/severe cGVHD at 2 years was $10 \%, 10 \%$, and $26 \%$ in the HAPLOD, MSD, and URD groups, respectively $(p=0.238$, URD vs. other, $p=0.09$, Fig. $1 \mathrm{~B}$ ).

In an exploratory multivariate analysis, allo-SCT from URD (but not from MSD) significantly enhanced the risk to develop grade 2-4 compared to HAPLOD (HR 3.86 95CI
1.47-10.14, $\mathrm{p}=0.006$ (Table A, supplementary file). Due to low number of events, MV was not performed for grade 3-4 acute GVHD and chronic GVHD.

\section{Survival, relapse, NRM, GRFS}

The 4-year OS and PFS (Fig. 2), GRFS and CIR and NRM for the entire cohort was 75\% (95CI: 65-86), 70\% (95CI: 60-82), 51\% (95CI: 41-65), 21\% (95CI: 13-33), and 9\% (95CI: 4-19), respectively. These outcomes were analyzed by donor type (HAPLOD vs MSD vs URD): 4-year OS was $76 \%$ vs $80 \%$ vs $68 \%(p=0.654)$; 4 -year PFS were $72 \%$ vs $69 \%$ vs $68 \%(p=0.9)$; CIR was $21 \%$ vs $31 \%$ vs $11 \%(p=$ 0.3 ), respectively. The 2 -year GRFS was $59 \%$ vs $50 \%$ vs $42 \%(p=0.5)$. The 4-year NRM was 7,0 and $21 \%(p=$ 0.067, Fig. 3). Exploratory multivariate analyses for OS, PFS, and GRFS did not show any difference between donor groups (Table B, supplementary file). Due to low number of events, MV was not performed for NRM and relapse.

Main events and outcome endpoints were analyzed within two donor groups (RD vs URD). Main patient characteristics are presented in supplemental file (Table C) and the two groups showed similar characteristics, except for intensity of conditioning regimen, which was higher in URD group. In the univariate analysis, OS, PFS and GRFS were not different, but the CI of grade 2-4 and the 4-year NRM were significantly higher in the URD group (58 vs $29 \%, p=0.008$ and 21 vs $4 \%, p=0.03$, respectively) (Fig. 1A, B supplementary file).

\section{Discussion}

This retrospective analysis suggests that allo-SCT allows for long-term disease control in poor prognosis PTCL, using any donor type. Indeed, 4-year OS, PFS, CIR, NRM, and GRFS for the entire cohort were 75, 70, 21, 9, and 51\%.

The patient population included in this study was obviously selected as $95 \%$ of them were in CR or PR before the transplantation. On the other hand, we dealt with heavily pre-treated patients (median number of previous chemotherapy lines was 3 ) and almost $30 \%$ of patients relapsed after high-dose chemotherapy. Therefore, this study cannot answer whether allo-SCT should be considered as first line consolidation treatment; however, it sheds some light on the real-life outcome of patients affected by R/R PTCL who received allo-SCT from different donors in a recent period of time. The median age (56 years) of our patients, slightly higher than reported in the literature, and HCT-CI score $\geq 3$ in $56 \%$ of patients outline that our population is representative of real-life medical practices.

A peculiar characteristic of this study was the high number of patients allografted from HAPLOD (43\%). In the 
Table 2 Univariate analysis.

\begin{tabular}{lclll}
\hline & $\begin{array}{l}\text { HAPLOD }(n=29) \\
\% \text { 95CI }\end{array}$ & $\begin{array}{l}\text { MSD }(n=20) \\
\% 95 \mathrm{CI}\end{array}$ & $\begin{array}{l}\text { URD }(n=19) \\
\% \text { 95CI }\end{array}$ & $p$ value \\
\hline $\begin{array}{l}\text { Acute GVHD } \\
\text { Grade 2-4 }\end{array}$ & $24 \%(13-46)$ & $35 \%(19-64)$ & $58 \%(39-85)$ & $\mathbf{0 . 0 2 4}$ \\
Grade 3-4 & $3 \%(1-24)$ & $15 \%(5-43)$ & $16 \%(6-45)$ & 0.169 \\
Chronic GVHD & & & & \\
Overall & $14 \%(6-34)$ & $15 \%(5-43)$ & $32 \%(16-61)$ & 0.284 \\
Moderate + severe & $10 \%(4-30)$ & $10 \%(3-37)$ & $26 \%(12-56)$ & 0.238 \\
NRM@4y & $7 \%(2-26)$ & $0 \%$ NA & $21 \%(9-50)$ & 0.067 \\
CIR@4y & $21 \%(10-42)$ & $31 \%(16-60)$ & $11 \%(3-39)$ & 0.369 \\
PFS@4y & $72 \%(58-91)$ & $69 \%(51-93)$ & $68 \%(50-93)$ & 0.988 \\
OS@4 y & $76 \%(62-93)$ & $80 \%(64-100)$ & $68 \%(50-93)$ & 0.654 \\
GRFS@2 y & $59 \%(43-80)$ & $50 \%(32-78)$ & $42 \%(25-71)$ & 0.547 \\
\hline
\end{tabular}

HAPLOD haploidentical donor, MSD matched sibling donor, URD unrelated donor, NRM nonrelapse mortality, $O S$ overall survival, $P F S$ progression free survival, $C I R$ cumulative incidence of relapse, GRFS graft-relapse free survival
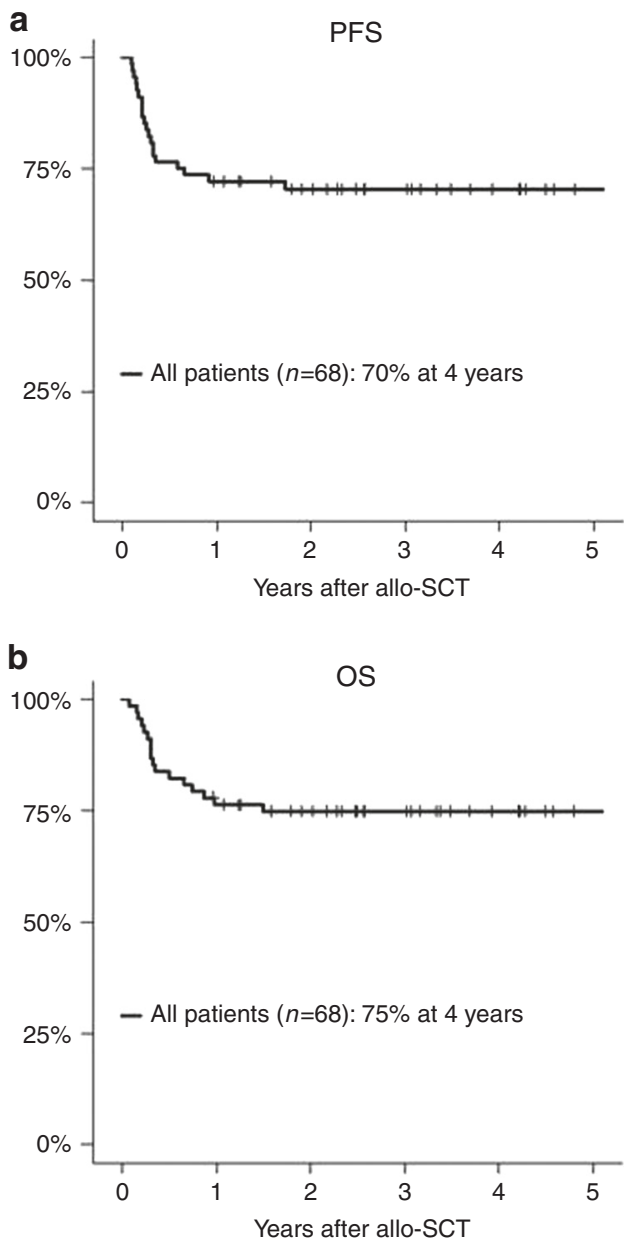

Fig. 2 Survival for the entire population. a Progression free survival; b overall survival.

literature, very few haplo-SCT have been reported in T-cell lymphoma. The CIBMTR included, in two studies [18, 19], 185 and 180 lymphoma patients received haplo-SCT and of

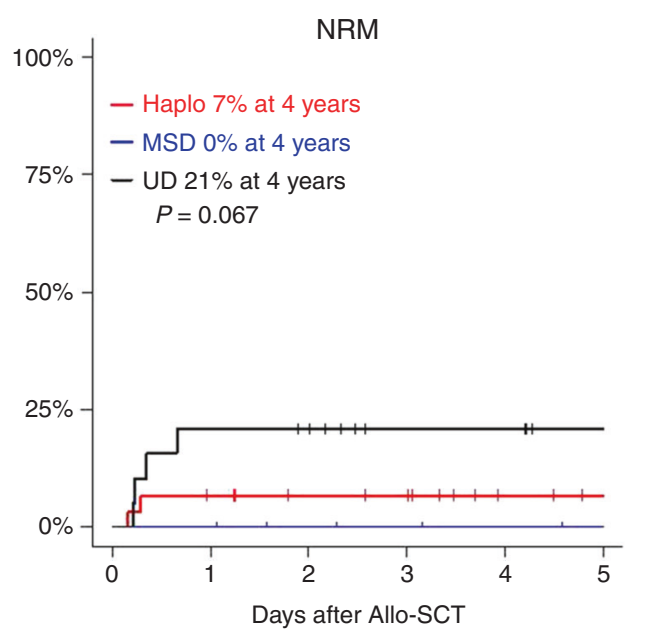

Fig. 3 Non-relapse mortality by donor type. Cumulative incidences of NRM by donor type.

these, 21 were T-cell lymphomas. In the Kanate's study [18], comparing haplo-SCT to URD-SCT, PFS, and OS were not significant affected by donor types, even if a trend toward a better outcome was observed for patients receiving URD without ATG compared to HAPLOD (3-y PFS 51 vs $32 \%$, OS 58 vs $36 \%$ ). The EBMT reported on 59 lymphoma patients treated with haplo-SCT with PT-Cy. In this paper, the number of T-cell lymphoma patients was unknown, but the relapse incidence in T-cell lymphoma was lower than diffuse large B cell lymphoma and higher than follicular lymphoma, with direct consequences on the PFS [20].

In this study, 4-year PFS and OS, and 2-year CIR were similar for all donor types, while the NRM was lower after haplo-SCT as compared to transplantation from URD. It is interesting to note that, in this series, the disease status before allo-SCT did not have any impact on the outcomes, probably due to an effective graft versus lymphoma effect, similarly to what was reported by Le Gouill et al. [28]. 
The CI of grade 2-4 aGVHD, but not 3-4, was significantly lower with HAPLOD than MSD and URD (35\% vs $24 \%$ and $58 \%, p=0.02$ ). This was slightly different from the CIBMTR studies, in which the authors found a statistical difference only for grade 3-4 aGVHD favoring HAPLOD as compared to URD [18], while no difference was apparent when compared to MSD [19]. On the other hand, we confirm the significantly lower incidence of cGVHD after haplo-SCT, similarly to CIBMTR studies.

In recent years, the mortality rate after allo-SCT has been lowered for several reasons [29]. Our cohort of patients was allografted in the last ten years, and the 2-year NRM was less than $10 \%$. There was a trend to higher 4-year NRM for patients receiving allo-SCT from URD compared to MSD or HAPLOD $(21 \%$ vs $0 \%$ vs $7 \%, p=0.06)$. In the CIBMTR studies, the NRM after haplo-SCT was similar to that observed with MDS and URD with or without ATG $[18,19]$. Similarly, the risk of grade $2-4$ was higher with URD than with RD. However, no difference in term of OS, PFS and relapse was observed in this analysis.

While comparison with previously published reports remains difficult, our results are promising. Indeed, in the literature, the PFS ranged from 29 to $80 \%$ and the OS from 41 to $80 \%$; the toxicity seems also to be lower in our study because the aGVHD ranged from 21 to $33 \%$ and the NRM from $12-34 \%$ [10, 28, 30-35]. Many reasons can contribute to these differences: patients selection and inclusion criteria, GVHD prophylaxis and conditioning regimen heterogeneity. Regarding this last point, Wulf et al. reported on 80 advanced patients (only $15 \%$ in CR at allo), receiving alloSCT from MRD (26\%), MURD (63\%) and mis-matched URD (11\%), using a myeloablative conditioning regimen (fludarabine, busulfan, and cyclophosphamide). The 5-y OS was $38 \%$, but the toxicity was extremely high (3 and 5-year NRM $32 \%$ and $46 \%$, respectively) [36]. Finally, almost all studies reported only MDS and URD, and very few patients were allografted from haploidentical donors [18, 19].

Globally comparing RD to URD is also of interest, as part of a pragmatic approach to offer allo-HSCT to all patients in need of these treatments. Indeed, for underrepresented minorities in international registries, or in lowto middle income countries, as in the context of acute crises such as COVID-19, allo-HSCT from RD represents an attractive opportunity because of its lower cost [37] and relative easiness to organize. In our study, while OS and PFS were not statistically different, grade $2-4$ acute GVHD and NRM were lower in the RD group, reinforcing this assumption. This may even open the door for further consideration in a wider population, but request should be prospectively addressed.

This study suffers from its retrospective nature and in particular from the evident patient selection, which can explain the outcomes observed. Furthermore, the sample size was limited, the period of inclusion was quite long with inherent heterogeneity regarding the treatment before transplantation, conditioning regimens, donor choice and supportive care.

However, this is a real-life selection of heavily pretreated patients, achieving a complete or partial remission.

This study indicates that allo-SCT is highly effective in PTCL, with low NRM and low relapse rates. Results from transplantation from RD compare favorably with URD, but confirmation is awaited with more patients.

\section{Compliance with ethical standards}

Conflict of interest The authors declare that they have no conflict of interest.

Publisher's note Springer Nature remains neutral with regard to jurisdictional claims in published maps and institutional affiliations.

\section{References}

1. Foss FM, Zinzani PL, Vose JM, Gascoyne RD, Rosen ST, Tobinai K. Peripheral T-cell lymphoma. Blood. 2011;117:6756-67.

2. Simon A, Peoch M, Casassus P, Deconinck E, Colombat P, Desablens B, et al. Upfront VIP-reinforced -ABVD (VIPrABVD) is not superior to $\mathrm{CHOP} / 21$ in newly diagnosed peripheral $\mathrm{T}$ cell lymphoma. Results of randomized phase III trial GOLEAMS-LTP95. Br J Haematol. 2010;151:159-66.

3. D'Amore F, Relander T, Lauritzsen GF, Jantunen E, Hagberg H, Anderson $\mathrm{H}$, et al. Up-front autologous stem-cell transplantation in peripheral T-cell lymphoma: NLG-T-01. J Clin Oncol. 2012;30:3093-9.

4. Reimer P, Rudiger T, Geissinger E, Weissinger F, Nerl C, Schmitz $\mathrm{N}$, et al. Autologous stem cell transplantation as first line therapy in peripheral $\mathrm{T}$ cell lymphomas: results of a prospective multicenter study. J Clin Oncol. 2009;27:106-13.

5. Chihara D, Fanale MA, Miranda RN, Noorani M, Westin JR, Nastoupil LJ, et al. The survival outcome of patients with relapsed/refractory peripheral $\mathrm{T}$ cell lymphoma not otherwised specified and angioimmunoblastic $\mathrm{T}$ cell lymphoma. $\mathrm{Br} \mathrm{J}$ Haematol. 2017;176:750-8.

6. Mak V, Hamm J, Chhanabbai M, SheinKier T, Klasa R, Sehn LH, et al. Survival of patients with peripheral $\mathrm{T}$ cell lymphoma after first relapse or progression: spectrum of disease and rare long-term survivors. J Clin Oncol. 2013;31:1970-6.

7. Ellin F, Landstrom J, Jekerman M, Relander T. Real world data on prognostic factors and treatment in peripheral $\mathrm{T}$ cell lymphomas: a study the Swedish Lymphoma Registry. Blood. 2014;124:1570-7.

8. Broccoli A, Argnani L, Zinzani PL. Peripheral T-cell lymphomas: Focusing on novel agents in relapsed and refractory disease. Cancer Treat Rev. 2017;60:120-9.

9. Le Gouill S, Milpied N, Buzyn A, De Latour RP, Vernant JP, Mohty M, et al. Graft -versus lymphoma effect for aggressive Tcell lymphomas in adults: a study by the Societe Francaise de Greffe de Moelle et de Therapie cellulaire. J Clin Oncol. 2008;26:2264-71.

10. Jacobsen ED, Kim HT, Cutler V, Ho VT, Koreth J, Fisher DC, et al. A large single-center experience with allogeneic stem-cell transplantation for peripheral T-cell non-Hodgkin lymphoma and advanced mycosis fungoides/Sezary syndrome. Ann Oncol. 2011;22:1608-13. 
11. Dodero A, Spina F, Narni F, Patriarca F, Cavattoni I, Benedetti F, et al. Allogeneic transplantation following a reduced-intensity conditioning regimen in relapsed/refractory peripheral $\mathrm{T}$ cell lymphomas: long term remissions and response to donor lymphocyte infusions support the role of a graft-versus-lymphoma effect. Leukemia. 2012;26:520-6.

12. Kim SM, Yoon SS, Suzuky R, Matsuno Y, Hy HG, Yhoshida T, et al. Comparison of outcome between autologous and allogeneic hematopoietc stem cell transplantation for peripheral T-cell lymphoma with central review of pathology. Leukemia. 2013;27:1394-440.

13. Loirat M, Chevallier P, Leux C, Moreau A, Bossard C, Guillaume $\mathrm{T}$, et al. Upfront allogeneic stem-cell transplantation for patients with nonlocalized untreated peripheral T-cell Lymphoma: an intention-to-treat analysis from a single center. Ann Oncol. 2015;26:386-92.

14. Luznik L, O'Donnell PV, Symons HJ, Chen AR, Leffell MS, Zahurak M, et al. HLA-haploidentical bone marrow transplantation for hematologic malignancies using nonmyeloablative conditioning and high-dose, posttransplantation cyclophosphamide. Biol Blood Marrow Transpl. 2008;14:641-50.

15. Burroughs LM, O'Donnell PV, Sandmaier BM, Storer BE, Luznik L, Symons HJ, et al. Comparison of outcomes of HLA-matched related, unrelated, or HLA-haploidentical related hematopoietic cell transplantation following nonmyeloablative conditioning for relapsed or refractory Hodgkin lymphoma. Biol Blood Marrow Transpl. 2008;14:1279-87.

16. Martínez C, Gayoso J, Canals C, Finel H, Peggs K, Dominietto A, et al. Post-transplantation cyclophosphamide-based haploidentical transplantation as alternative to matched sibling or unrelated donor transplantation for hodgkin lymphoma: a registry study of the Lymphoma Working Party of the European Society for Blood and Marrow Transplantation. J Clin Oncol. 2017;35:3425-32.

17. Castagna L, Bramanti S, Devillier R, Sarina B, Crocchiolo R, Furst $\mathrm{S}$, et al. Haploidentical transplantation with post-infusion cyclophosphamide in advanced Hodgkin lymphoma. Bone Marrow Transpl. 2017;52:683-8.

18. Kanate AS, Mussetti A, Kharfan-Dabaja MA, Ahn KW, DiGilio A, Beitinjaneh A, et al. Reduced-intensity transplantation for lymphomas using haploidentical related donors vs HLA-matched unrelated donors. Blood. 2016;127:938-47.

19. Ghosh N, Karmali R, Rocha V, Ahn KW, DiGilio A, Hari PN, et al. Reduced-intensity transplantation for lymphomas using haploidentical related donors versus hla-matched sibling donors: a center for international blood and marrow transplant research analysis. J Clin Oncol. 2016;34:3141-9.

20. Dietrich S, Finel H, Martinez C, Tischer J, Blaise D, Chevallier P, et al. Post-transplant cyclophosphamide-based haplo-identical transplantation as alternative to matched sibling or unrelated donor transplantation for non-Hodgkin lymphoma: a registry study by the European society for blood and marrow transplantation. Leukemia. 2016;30:2086-9.

21. Dreger P, Sureda A, Ahn KW, Eapen M, Litovich C, Finel H, et al. PTCy-based haploidentical vs matched related or unrelated donor reduced-intensity conditioning transplant for DLBCL. Blood Adv. 2019;3:360-9.

22. Gauthier J, Castagna L, Garnier F, Guillaume T, Socié G, Maury $\mathrm{S}$, et al. Reduced-intensity and non-myeloablative allogeneic stem cell transplantation from alternative HLA-mismatched donors for Hodgkin lymphoma: a study by the French Society of Bone Marrow Transplantation and Cellular Therapy. Bone Marrow Transpl. 2017;52:689-96.

23. Kanakry JA, Kasamon YL, Gocke CD, Tsai HL, Davis-Sproul J, Ghosh N, et al. Outcomes of related donor HLA-identical or HLA-haploidentical allogeneic blood or marrow transplantation for peripheral $\mathrm{T}$ cell lymphoma. Biol Blood Marrow Transpl. 2013;19:602-6.
24. Bazarbachi A, Boumendil A, Finel H, Castagna L, Dominietto A, Blaise D, et al. Influence of donor type, stem cell source and conditioning on outcomes after haploidentical transplant for lymphoma- a LWP-EBMT study. $\mathrm{Br} \mathrm{J}$ Haematol. 2020;188:745-56.

25. Sorror ML, Logan BR, Zhu X, Rizzo JD, Cooke KR, McCarthy PL, et al. Prospective validation of the predictive power of hematopoietic cell transplantation comorbidity index: a Center for International Blood and Marrow Transplant Research Study. Biol Bone Marrow Transplant. 2015;21:1479-87.

26. Przepiorka D, Weisdorf D, Martin P, Klingemann HG, Beatty P, Hows J, et al. 1994 Consensus conference on acute GVHD grading. Bone Marrow Transpl. 1995;15:825-8.

27. Jagasia MH, Greinix HT, Arora M, Williams KM, Wolff D, Cowen EW, et al. National Institutes of Health consensus development project on criteria for clinical trials in chronic graft-versushost disease: I. The 2014 Diagnosis and Staging Working Group report. Biol Blood Marrow Transpl. 2015;21:389-401.

28. Le Gouill S, Milpied N, Buzyn A, De Latour RP, Vernant JP, Mohty M, et al. Graft-versus-lymphoma effect for aggressive Tcell lymphomas in adults: a study by the Société Francaise de Greffe de Moëlle et de Thérapie Cellulaire. J Clin Oncol. 2008;26:2264-71.

29. Gooley TA, Chien JW, Pergam SA, Hingorani S, Sorror ML, Boeckh $M$, et al. Reduced mortality after allogeneic hematopoietic-cell transplantation. $\mathrm{N}$ Engl J Med. 2010;363:2091-101.

30. Smith SM, Burns LJ, van Besien K, Lerademacher J, He W, Fenske TS, et al. Hematopoietic cell transplantation for systemic mature T-cell non-Hodgkin lymphoma. J Clin Oncol. 2013;31:3100-9.

31. Kyriakou C, Canals C, Finke J, Kobbe G, Harousseau JL, Kolb $\mathrm{HJ}$, et al. Allogeneic stem cell transplantation is able to induce long-term remissions in angioimmunoblastic T-cell lymphoma: a retrospective study from the lymphoma working party of the European group for blood and marrow transplantation. J Clin Oncol. 2009;27:3951-8.

32. Dodero A, Spina F, Narni F, Patriarca F, Cavattoni I, Benedetti F, et al. Allogeneic transplantation following a reduced-intensity conditioning regimen in relapsed/refractory peripheral T-cell lymphomas: long-term remissions and response to donor lymphocyte infusions support the role of a graft-versus-lymphoma effect. Leukemia. 2012;26:520-6.

33. Zain J, Palmer JM, Delioukina M, Thomas S, Tsai NC, Nademanee A, et al. Allogeneic hematopoietic cell transplant for peripheral T-cell non-Hodgkin lymphoma results in long-term disease control. Leuk Lymphoma. 2011;52:1463-73.

34. Delioukina M, Zain J, Palmer JM, Tsai N, Thomas S, Forman S. Reduced-intensity allogeneic hematopoietic cell transplantation using fludarabine-melphalan conditioning for treatment of mature T-cell lymphomas. Bone Marrow Transpl. 2012;47:65-72.

35. Czajczynska A, Günther A, Repp R, Humpe A, Schub N, Raff T, et al. Allogeneic stem cell transplantation with BEAM and alemtuzumab conditioning immediately after remission induction has curative potential in advanced T-cell non-Hodgkin's lymphoma. Biol Blood Marrow Transpl. 2013;19:1632-7.

36. Wulf G, Hasenkamp J, Jung W, Wilhelm C, Held G, Nickelsen M, et al. Allogeneic stem cell transplantation for patients with relapsed or refractory T-cell lymphoma: efficacy of lymphomadirected conditioning against advanced disease. Bone Marrow Transpl. 2019;54:877-84.

37. Debals-Gonthier M, Siani C, Faucher C, Touzani R, LemariéBasset C, Chabannon C, et al. Cost-effectiveness analysis of haploidentical vs matched unrelated allogeneic hematopoietic stem cells transplantation in patients older than 55 years. Bone Marrow Transpl. 2018;53:1096-104. 